Murolo, Norberto Leonardo

\title{
La pantalla pirata : usos y apropiaciones del audiovisual en Internet por parte de jóvenes
}

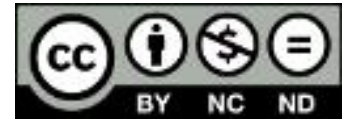

Esta obra está bajo una Licencia Creative Commons Argentina.

Atribución - No Comercial - Sin Obra Derivada 2.5

https://creativecommons.org/licenses/by-nc-nd/2.5/ar/

Documento descargado de RIDAA-UNQ Repositorio Institucional Digital de Acceso Abierto de la Universidad Nacional de Quilmes de la Universidad Nacional de Quilmes

\section{Cita recomendada:}

Murolo, N. L. (2016). La pantalla pirata: usos y apropiaciones del audiovisual en Internet por parte de jóvenes. Divulgatio, 1(1). Disponible en RIDAA-UNQ Repositorio Institucional Digital de Acceso Abierto de la Universidad Nacional de Quilmes http://ridaa.unq.edu.ar/handle/20.500.11807/262 


\title{
La pantalla pirata: usos y apropiaciones del audiovisual en Internet por parte de jóvenes
}

\section{The pirate screen: uses and appropriations of the audiovisual in internet by the young}

ARTÍCULO

\begin{abstract}
Norberto Leonardo Murolo
Universidad Nacional de Quilmes. Consejo Nacional de Investigaciones Científicas y Técnicas, Argentina. nlmurolo@unq.edu.ar
\end{abstract}

Recibido: julio del 2016

Aceptado: agosto del 2016

\section{Resumen}

El presente trabajo se focaliza en los usos y apropiaciones de material audiovisual en Internet, específicamente, mediante las prácticas de descarga y visualización de páginas piratas. En términos teóricos, se entiende a las tecnologías, siguiendo a Raymond Wiliams (2011), desde los usos y no en su variante determinista tecnológica o como tecnología sintomática. La noción pirata es retomado desde Henry Jenkins (2006 y 2010) para caracterizar al sujeto de la comunicación que usa las tecnologías digitales, el cual se apropia del material de Internet y lo resignifica otorgándole un espacio en su constitución identitaria como fan. Por otra parte, las ideas de apropiaciones, objetizaciones, incorporaciones y conversiones son trabajadas desde los postulados de Roger Silverstone, Eric Hirsh y David Morley (1997). En tanto, el trabajo se asienta -en lo metodológico cualitativo- en entrevistas semiestructuradas a jóvenes de 14 a 21 años del partido de Quilmes, con quienes se dialogó acerca de los usos, apropiaciones, y siginificaciones que le otorgaban a la industria cultural audiovisual digital.

Palabras claves: jóvenes; piratas; audiovisual; pantallas; descarga.

\section{Abstract}

The following paper focuses on the uses and appropriations of the audiovisual material in Internet, specifically, through the practices of downloading and viewing of pirate websites. In theoretical terms, it is understood to technologies, following Raymund Williams (2011), from their uses and not in their technological deterministic variant or symptomatic technology. The pirate notion is echoed by Henry Jenkins (2006 and 2010) to characterize the subject of the communication that uses the digital technologies, who appropriates of the materian of Internet and resignifies it, giving it a space in his constitution as fan. Moreover, the ideas of appropriations, objetivizations, additions and conversions are worked from the postulates of Roger Silverstone, Eric Hirsh and David Morley (1997). The work is based-in qualitative methodological- on semi structured interviews to young people from 14 to 21 years old from the location of Quilmes, with whom we dialogued about the uses, appropriations and significations they gave to the cultural industry of the digital audiovisual.

Keywords: youngs, pirate, audiovisual, screens, download. 


\section{Introducción}

En la contemporaneidad asistimos a diferentes modos de consumo de la industria cultural. En medio de una cultura digitalizada, las empresas del sector se reconfiguran más lentamente que los desarrollos tecnológicos y proponen diferentes modelos de negocios, generalmente insuficientes a la hora de comprender nuevas lógicas de consumos, usos y apropiaciones por parte de los sujetos sociales.

El presente trabajo se interesa en los usos y apropiaciones audiovisuales en los márgenes del mercado. La digitalización como proceso tecnológico permitió la transposición de diferentes materiales lingüísticos en el formato de dato. Sin embargo, los cambios significativos se dan en marco de la digitalización como proceso cultural (Doueihi, 2010). Los usos y apropiaciones sociales que redundan en nuevos esquemas de consumos culturales de materiales de la industria cultural dibujan un nuevo escenario. Los sujetos sociales consumen películas, series televisivas, sagas de libros, videojuegos, música, softwares y demás producciones en medio de nuevas lógicas a las que se practicaban en el siglo pasado. El cambio paulatino es de orden cultural y configuró un nuevo sujeto de la comunicación que transformó las audiencias y los espectadores de la radio, el cine y la televisión en prosumidores, fans y piratas (Jenkins, 2006, 2010). Se trata de sujetos que consumen, producen, intervienen en el mensaje de nuevos medios, y en medios clásicos como la televisión.

En este escenario cambiante, son los jóvenes quienes primero adoptan, crean, producen y reproducen lógicas de consumo. De allí que el estudio se focaliza en varones y mujeres de 14 a 21 años para analizar un sujeto de la comunicación innovador en sus prácticas de consumo de la industria cultural.

El artículo presenta primeramente los espacios de circulación de material audiovisual en Internet, señalando su carácter de ilegal o en los márgenes del mercado. Luego se interesa en los usos y apropiaciones que los jóvenes realizan de estos materiales.

\section{Metodología de abordaje}

Para ocuparnos de la descarga y visualización de material de Internet la investigación se basa en una indagación de tipo cualitativa. En primer lugar, en literatura especializada que tematice problemáticas ligadas a los derechos de autor y la proliferación de los usos de descarga de internet de material protegido. Asimismo, a raíz de tratarse de temas novedosos nos resulta interesante indagar publicaciones periodísticas específicas en relación con acontecimientos ligados al pedido de bloqueo de páginas donde circula material con derechos de autor, como en los casos argentinos Cuevana y Taringa o el caso de resonancia mundial, Megaupload. 
Para acceder a información empírica sobre los consumos culturales juveniles a través de las pantallas, la perspectiva metodológica cualitativa se asienta en entrevistas cualitativas realizadas a jóvenes de 14 a 21 años de edad del partido de Quilmes, elegidos como referentes empíricos, donde tematizan el uso de series y películas de cine y televisión mediante internet. A su vez, aparecen como usos frecuentes la descarga de otros tipos de materiales como libros, música, software y videojuegos, que no haremos referencia por focalizarnos especialmente en el terreno del audiovisual.

En este espacio dialógico surgen las motivaciones y valoraciones que los jóvenes atribuyen a la facilidad, beneficio y enriquecimiento que les provee descargar archivos de Internet. Asimismo, frente a las imposiciones hegemónicas del mercado sobre lo permitido y lo prohibido, reflexionan acerca de ser o no ser pirata.

\section{Las pantallas piratas}

Una de las prácticas más recurrentes en Internet es la descarga de archivos: de texto, fotográficos, musicales, de software, de videojuegos, así como también de series y películas. En este escenario digital, la industria cultural circula la mayoría de las veces de manera ilegal. Páginas web como Mega, softwares como jdownloader, Utorrent o los P2P -peer to peer- (que comparten archivos de una computadora a otra, al estilo Ares o Kazaa) son los modos más usuales.

El universo del lenguaje audiovisual supone uno de los materiales culturales preferidos por los jóvenes. De esta manera, la descarga y/o visualización en línea de audiovisual representan usos y apropiaciones generalizados y en poco tiempo incorporados como prácticas sociales. Como característica a destacar de estos usos, principalmente, se evidencia que los consumos audiovisuales obedecen a televisión y cine. Es decir, viejas pantallas en nuevas pantallas. La mayoría de los jóvenes entrevistados ve al menos una serie televisiva o películas online en vez de consumirlas por su medio de origen.

Asimismo, se encuentran los sitios al estilo YouTube que alojan material audiovisual destinado a nuevas pantallas como videoclips y tráileres (otrora en pleno apogeo en televisión y en cine, respectivamente), a la vez que generan su propio repertorio de géneros, destacándose el video amateur: youtubers, tutoriales y fanvideos. Estas narraciones también forman parte de los discursos juveniles, pero en esta oportunidad no haremos referencia a ellas porque nos interesa puntualizar en los usos y apropiaciones acusados por el sistema de ilegales o en los márgenes del mercado.

Propuestas como Stop Online Piracy Act (SOPA) y la Ley PROTECT IP (PIPA) ${ }^{1}$ apuntan directamente a lo que se denomina como piratería: el uso de material en Internet con propiedad

\footnotetext{
1 "Las claves de las leyes SOPA y PIPA". En EI PAÍS, 19/01/2012. Disponible en:
} 
intelectual y no autorizados por el autor. La oposición online a los dos proyectos se difuminó rápidamente una vez que se corrió la voz de que SOPA / PIPA contenía disposiciones que exigían la elaboración de listas negras de sitios web. En una carta abierta al Congreso, el cofundador de Google, Sergey Brin, y otros prominentes empresarios de Internet afirmó que la legislación daría al gobierno de los EE.UU. "poder para censurar la web utilizando técnicas similares a las empleadas en China e Irán" (Bugvila, 2012, p. 10).

\section{Dos casos argentinos y una disputa a escala mundial: Cuevana, Taringa y Megaupload}

La mayoría de los jóvenes entrevistados descargó -y lo sigue haciendo- algún tipo de material de la red sin advertir que comete un ilícito. Existen páginas de descarga y visualización de series y películas de diferentes puntos del mundo y sería inútil realizar un inventario de las mismas. En nuestro recorrido nos interesa caracterizar de manera genérica dos casos argentinos. Esto, en primer lugar, porque son versiones nacionales de esta modalidad de oferta y consumo; en segundo lugar, porque son los espacios más mencionados por los jóvenes: Cuevana y Taringa -se constituyen como lugares de permanencia prolongada en las visitas virtuales $^{2}$. El primero es un portal que permite la visualización de películas y series en la misma página mediante sitios externos, como Megaupload o Rapidshare, que alojan el material. La página se propone como pantalla que reproduce ese archivo en formatos avi, mpg o mp4. Estas páginas no abren el juego a que cada usuario postee sus videos, sino que proporcionan un menú de series y películas. En el caso de Cuevana, en algún momento también propuso ver televisión en vivo. Ello le costó que el canal de televisión abierta Telefé le iniciara acciones legales. Por aquel entonces el diario La Nación titulaba "Una de piratas que se libra en el país" y proponía un debate sobre la legislación actual en materia de Propiedad Intelectual y Marcas ${ }^{3}$. Asimismo, en febrero de 2013 el canal norteamericano HBO solicitó a la justicia argentina el bloqueo de Cuevana por emitir sin permisos la serie Epitafios. Solicitud que fue denegada 4 .

Como sea, el caso Cuevana fue tomado por los medios de comunicación masiva como índice de singularidad tanto para poner de manifiesto que se trataba de un "invento argentino",

http://tecnologia.elpais.com/tecnologia/2012/01/19/actualidad/1326967261 850215.html (Consultado el 25 de julio de 2016).

${ }^{2}$ Se conocen diversos portales de Internet donde ver y descargar material audiovisual. No es de nuestro interés realizar un inventario de estos espacios. Haremos referencia con mayor énfasis los casos de Cuevana y Taringa por tratarse de apuestas argentinas y envueltas en disputas legales. Asimismo, mencionaremos el caso Megaupload por ser emblema a escala mundial del tema de Propiedad Intelectual y Marcas en Internet.

3 "Una de piratas se libra en el país". En LA NACIÓN, 30/10/2011. Disponible en: http://www.lanacion.com.ar/1418856-una-de-piratas-que-se-libra-en-el-pais (Consultado el 25 de julio de 2016).

4 "La justicia porteña rechaza el pedido de bloqueo a Cuevana". En LA NACIÓN, 06/02/2013. Disponible en: http://www.lanacion.com.ar/1552339-la-justicia-portena-rechaza-el-pedido-de-bloqueo-a-cuevana (Consultado el 25 de julio de 2016).

5 “El gran invento argentino". En Clarín, 06/04/2011. Disponible en: http://www.rollingstone.com.ar/1363354cuevana-el-gran-invento-argentino (Consultado el 31 de julio de 2016). 
como para narrar de manera novelesca la historia de su creación y su devenir judicial ${ }^{6}$. Cuevana ya formaría parte de la cultura popular nacional.

El caso de Taringa es similar en algunos puntos. Se trata de una página web donde se encuentran enlaces para descargar todo tipo de material. Por un tiempo estuvo de moda para quienes buscaban material audiovisual para guardarlo en su computadora. En él se hallan libros, discos y videojuegos, además de funcionar como foro de respuestas y novedades.

Los espacios de visualización en línea, que en algunos casos tienen la opción de la descarga superan, de algún modo, la propuesta de la simple descarga ya que no ocupan espacio y no hay que esperar horas para poder ver una película o una serie.

Taringa, de origen argentino, se vio envuelto en un caso judicial similar al de Cuevana siendo acusado de facilitar material con derechos de autor en la web. Taringa aduce ser un foro y en términos formales esto es cierto, un usuario de la página con un nickname y una clave accede a un foro donde postea, puede seguir y ser seguido, comentar y ser comentado, puede recibir y dar puntajes. Los puntos, en Taringa, se obtienen brindando un buen post. Quizás sea cierto que los creadores de Taringa hayan ideado simplemente un foro y los usos sociales lo llevaron a convertirse en un sitio de enlaces a otras ventanas donde descargar material.

Estas ventanas son generalmente direcciones a sitios en el extranjero, como Megaupload, el caso que desencadenó la posibilidad de las leyes de censura digital. El cierre de Megaupload fue llevado adelante por el FBI a petición de un juez federal ${ }^{7}$. Enseguida, este caso paradigma de la contemporaneidad alertó a los cibernautas y se creó una conciencia política a favor de la libertad en internet.

Según Miguel Moreno Muñoz (2012) la actividad de 180 millones de usuarios y 50 millones de visitas diarias a Megaupload habría generado "daños por copyright" estimados en 500 millones de dólares. Esto evidencia que la disputa hegemónica por la posibilidad de acceso y descarga de material de internet es un factor de poder y presión en el mercado.

En su modalidad básica -gratuita-, Megaupload permitía subir archivos de hasta 2 GB y descargas de hasta 1 GB. La modalidad Premium -por unos 60 euros anuales- eliminaba el límite

6 "La historia detrás de Cuevana". En Rolling Stone, 01/11/2011. Disponible en: http://www.rollingstone.com.ar/1419593-la-historia-detras-de-cuevana. "La historia detrás de Cuevana". En Rolling Stone, 01/11/2011. Disponible en: http://www.rollingstone.com.ar/1419594 "La muerte lenta de Cuevana". En Rolling Stone, 08/06/2012. Disponible en: http://www.rollingstone.com.ar/1479998-la-muerte-lenta-de-cuevana “¿Revive Cuevana?”. En Rolling Stone, 29/03/2013. Disponible en: http://www.rollingstone.com.ar/1567389revive-cuevana (Consultados el 31 de julio de 2016).

${ }^{7}$ El FBI intervino la sede central de la empresa: Arrestó a cuatro responsables de la página y ordenó la detención de tres acusados más por delitos de piratería y blanqueo de capitales.

- Denuncia cursada por un jurado de EE.UU. el 5 de enero de 2012. Acusaba a los responsables de la web de blanqueo de capitales y violación de la propiedad intelectual: "Durante más de cinco años la organización ha operado páginas web que reproducían ilegalmente y distribuían infringiendo las leyes de la propiedad intelectual obras que incluían películas antes de su estreno comercial, música, programas de televisión, libros electrónicos y software de entretenimiento a una escala masiva".

"Los conspiradores se negaron a cerrar cuentas de usuarios que infringían los derechos de autor"; sólo retiraban "selectivamente" los enlaces denunciados y después lo comunicaban "a los poseedores de derechos" (Moreno Muñoz, 2012). 
de subida y permitía las descargas de hasta 100 GB y combinar varios ficheros. Megaupload contaba además con la plataforma Megavideo, desde la que podían verse series y películas en streaming, sin necesidad de descargarlas. En total, la empresa podría haber logrado más de mil millones de visitas (50 millones al día), involucrando a más de 150 millones de usuarios registrados (en torno al 4\% del tráfico global en Internet) (Moreno Muñoz, 2012).

El caso se posicionó como emblema y activó la capacidad de presión al poder político por parte del mercado para defender sus intereses, ya que el universo digital vino siendo legislado muy lentamente. La relación de las grandes empresas de entretenimiento con el universo de internet también se trata de un intercambio de negociaciones constantes. Por ejemplo, se ha informado que "YouTube ha establecido numerosos acuerdos con proveedores de contenido como CBS, BBC, Universal Music Group, Sony Music Group, Warner Music Group, NBA y The Sundance Channel, entre otros" (Murolo, 2010). Al tiempo que el fenómeno Megaupload no pasó desapercibido a la industria audiovisual. De ser cierta la información publicada por el diario New Zealand Herald, ejecutivos de varios estudios de Hollywood (entre ellos, Disney, Warner Bros, Fox y Turner Broadcasting) buscaron acuerdos comerciales con el portal Megaupload, pese a tratarse de empresas que habían materializado en las instancias competentes numerosas quejas por violaciones de sus derechos de autor (Moreno Muñoz, 2012, p. 6).

Estos sitios y la masividad que toman sus usos sociales incorporados permiten reflexionar sobre si finalmente, quizás como condición de época, ser un joven que usa tecnologías es sinónimo de ser pirata. Es la creencia que la hegemonía de los sentidos, encarnada en este caso por el mercado, quiere investir a los partidarios de la liberación de los contenidos de internet.

Entrado el siglo XX las llamadas "industrias culturales" se afianzaron como tales. Como se ha analizado desde la teoría de la economía política de la comunicación, fueron diagramando y afianzando sus "modelos de negocios". Los cuales se asentaban en lo analógico: objetos con una carga de valor simbólico que prevalecía a la de cambio, pero no dejaban de ser mercancías tangibles como la televisión, el libro, el disco. La digitalización trastocó estos productos, muchos los hizo intangibles, al tiempo que el paso de una obra a formato de dato hace que la réplica sea igualmente válida. No obstante, como sostenían Adorno y Horkheimer (1970) no podía hablarse de "un original" de la industria cultural porque el libro y el disco eran objetos industrializados y cotidianamente llamamos "original" cuando no eran fotocopia o grabación casera.

El mundo de lo pirata y el consumo de la industria cultural en los márgenes del mercado no son algo novedoso. Los casetes en los ' 80 y los VHS a principio de los '90 eran copiados, "truchados", como una práctica que comenzaba a hacer tan habitual como alquilar películas o comprar casetes en disquerías. Luego, la digitalización logró sus propias maneras de piratería: el $C D$, el DVD, la descarga de internet, compartir mediante un pendrive, son prácticas comunicacionales que podríamos llamar usuales en la contemporaneidad y que se suman a otras como "colgarse del cable" o "robar" wifi. 
En la digitalización el original es más difuso, para no decir nulo. Es un problema de los productores de estas industrias culturales generar un nuevo modelo de negocios. La digitalización expandió los productos culturales y llegó a cada computadora con conexión a Internet. Los jóvenes que descargan materiales de internet se encuentran ajenos a las grandes decisiones mercantiles y simplemente incorporan prácticas sociales entre pares.

Casos puntuales como bandas musicales que proponen ver su video o descargar una canción de su disco de manera gratuita mediante la web, son prácticas conscientes de época. Al mismo tiempo, se encuentran sitios como Spotify, iTunes o Netflix donde acceder mediante pago a obras musicales y audiovisuales. Estos espacios gradualmente aumentan sus precios y en algunos casos se encuentran restringidos a determinadas áreas geográficas. Exitosos o no son intentos mercantiles de proponer nuevos modelos de negocios en las plataformas digitales.

En este contexto, la descarga y visualización gratuita no disminuye, al tiempo que los sujetos solicitan de algún modo una liberación de estos productos culturales a la luz de las disputas por la hegemonía de los usos y apropiaciones sociales de los que forman parte.

Es menester del mercado defender sus intereses $y$, como lo hace históricamente, proponer reglas y rejas, felicidad y precio, a los sujetos consumidores y ciudadanos. En ese sentido, la actividad política de los sujetos se constituye en resistir en defensa de sus conquistas en materia de prácticas sociales.

\section{Series, películas y nuevas pantallas}

La posmodernidad se inscribe en una perspectiva relativista y posturas lábiles ante los más diversos órdenes de la vida en sociedad. Zygmunt Bauman (2009) emplea la metáfora del líquido, sosteniendo que seguimos en la Modernidad pero en una faceta incontenible y cambiante. El tiempo, la identidad, los miedos, el amor, la vida son líquidos y no se puede planear un futuro lejano en casi ningún aspecto. No compartimos las posturas posmodernas de incontenibilidad ni de caída de grandes relatos. La política partidaria, las creencias religiosas, el desarrollo científico y las ideologías demuestran renovadamente lo contrario, forman parte de nuestra configuración de subjetividad aun en la contemporaneidad. Sin embargo, es interesante un aspecto que los posmodernos sostienen, otorgándole, dentro de lo efímero, una señalada importancia a la imagen en la contemporaneidad. La cultura de la imagen, que no es novedosa, se asienta en la omnipresencia de los medios de comunicación audiovisuales construidos con imágenes de manera metonímica entendidas como de videoclip, fugaces y en constante ebullición. La imagen es valorada y consumida a diario en diferentes soportes, postulándose como uno de los principales lenguajes.

Los jóvenes entrevistados tienen una relación directa con la imagen. La consumen, la construyen, la comparten. Son conscientes de que una dimensión de ellos es imagen y que pueden tener de algún modo el control sobre ella. 
En relación con el universo del lenguaje audiovisual, la mayoría de ellos consume una serie televisiva y películas, videoclips musicales, videos amateurs, publicidad, además de una variedad de imágenes fijas en publicaciones y en la vía pública. Algunos de estos consumos tienen que ver con épocas anteriores (aunque siempre con la actual), como son el cine y la televisión. La marca de época estriba en que consumen estas producciones televisivas y cinematográficas mediante nuevas pantallas.

Las series de televisión forman parte de la identidad de los jóvenes contemporáneos, la amplia mayoría de los entrevistados cuentan que ven estas producciones de manera adictiva ${ }^{8}$.

A pesar de que cuando se les pregunta a qué les remite la palabra tecnología y la respuesta incluya la televisión -junto con computadoras y teléfonos- no es una tecnología que empleen con asiduidad. Los jóvenes producen, sin saberlo, un desplazamiento hacia otras tecnologías. Por un lado, estas pantallas le plantean una competencia a la televisión dado que contando con internet se puede acceder a los videos cuando uno lo desee. De todos modos, la televisión existe y sus formatos ocupan un lugar importante en el universo mediático juvenil, aunque afirman consumirla en pocas ocasiones.

Miro pocas cosas: me gusta ver Los Simpson, me gusta ver Capusotto, y mirá lo que te digo no sé si algo más me gusta ver. Escuela de Rock la encuentro en cualquier canal y me pongo a verla, pero la televisión como programación no, muy mala para mi opinión (Facundo, 17 años, Villa La Florida).

Antes miraba Friends, The Big Bang Theory, pero ahora no miro mucha tele (Marianela, 19 años, Quilmes Centro).

Ahora no miro tanto tele, porque ahora me interesan más las películas, que en la tele lo que más miraba cuando era más chico eran dibujos. Si necesito ver algo, una serie o una película lo busco por Internet porque es más fácil (Joaquín, 15 años, Quilmes Centro).

Me encanta Glee, esa es la que veo todos los viernes por Internet religiosamente porque en Fox me la pasan tarde. Porque es así: Fox la pasa atrasada y yo estoy viendo lo más nuevo, ¿entendés? Porque ellos, por ahí, es la cuarta temporada la que van ahora y están pasando el tercer capítulo creo, el cuarto, y yo voy por el dieciséis. Entonces, en vez de ver la tele, lo veo por Internet y ya está. En realidad, los jueves ya está, porque lo pasan los jueves a la noche. Entonces, se ve que en los Estados Unidos cuando terminan el capítulo, cuando lo terminaron de filmar, ya lo suben a la computadora. O sea que, nada, una hora. Pero, después, son todos en inglés. Entonces, si lo querés subtitulado, el viernes a la mañana o por ahí, ya lo tenés. O sea, pongo "Glee online" y me metí. Descargar no porque sé que es al pedo. Porque yo veo el capítulo y ya está. No es como una novela que vas a ver ochenta veces el capítulo. Por ahí pasé Fox, vi que repitió un capítulo y me quedé mirándolo (Nair, 18 años, Quilmes Centro).

La tele no la prendo. La tengo en la pieza, pero no la prendo. No me gustan los programas que hay, son muy vacíos. No me interesa (Agustina, 17 años, Quilmes Centro).

No miro mucha tele igual, eh. A la noche, capaz que alguna serie que esté mirando en el momento, que sigo en el momento. Por ahí, sí, me engancho con eso. En el horario que no

8 "Las series de TV y nuestra identidad". En LA NACION, 20/10/2012. Disponible en: http://www.lanacion.com.ar/1518882-las-series-de-tv-y-nuestra-identidad (Consultado el 25 de julio de 2016). 
hago nada, que llego a mi casa y que por ahí tengo un rato para estar en la computadora o para mirar un poco de tele, o leer un libro, o lo que fuera, o estudiar. En ese horario por ahí, sí, en ese momento... alguna serie o por ahí, sí, a la noche miro el Diario de medianoche (Lautaro, 17 años, Quilmes Centro).

La particularidad no es una supresión de la televisión como contadora de historias, sino que se produce un desplazamiento de esas historias a nuevas plataformas. En otras palabras, se trata de que los jóvenes contemporáneos continúan narrándose a través de relatos televisivos pero los consumen a través de nuevas pantallas como YouTube, Cuevana, Taringa, SeriesYonkis, o las descargan por UTorrent. Esto nos lleva a reflexionar que aquel lugar privilegiado que ocupaba la televisión en el hogar, como un integrante más de la familia en momentos como la cena, y luego de su paso a la privacidad de la habitación de jóvenes y padres, deviene en una tercera faceta que ya no es protagonizada por el aparato o dispositivo sino por sus contenidos. Entonces es cuando la privacidad del consumo televisivo se desplaza a la computadora personal y a las tablets, suprimiendo la idea de grilla: se ven las series y programas cuando se quiere y donde se quiere.

En este marco, la hegemonía de las historias televisivas la detenta, como en cine, Estados Unidos. De la impronta sincrónica cultural es interesante subrayar que las series preferidas de los jóvenes entrevistados son The Walking Dead, Ones Upon a Time, Friends, Glee, The Big Bang Theory, Los Simpson, entre otras. Todas ellas de ficción y abarcan desde el terror y el suspenso hasta la sitcom, el musical y la comedia ${ }^{9}$.

Vemos recurrentes referencias a estos envíos televisivos en los extractos de las entrevistas, con lo cual se infiere que pertenecen a un consumo juvenil cotidiano y participan como historias a la construcción de identidades y fanatismos propios de la adolescencia.

Series veo varias, Friends, The Big Bang Theory, Amas de casa desesperadas, Glee, American Horror History, The Walking Dead (poco), The Office en I-SAT, Los Simpson; Futurama, me encanta por ejemplo. En internet las veo en Seriesyonkis.com, veo Glee y todas las que se superponen con las de canal de aire (cuando me pierdo capítulos), Queer as folk es la única que me descargué, después el resto todas online. De Friends, por ejemplo, tengo todas las temporadas que las compré en Yenni. Después descargo música, imágenes (muchísimas) y porno (Jeremías, 22 años, Quilmes Centro).

Veo series, eso sí. Series veo un montón. La principal es Once upom a time, que me encanta, es la que estoy viendo todos los días. Después hay una que se llama Sherlock, que es inglesa, que es buenísima. Después Pretty little liars. Scream y Gossip girl. ¿Qué más vi? Hay una que se llama Chica rara, de MTV también, esa también. Y no, básicamente esas. Por la tele están re atrasadas. Sale el capítulo allá y a las doce, una, acá ya está y me lo pongo a ver. Porque soy re adicta con las series, pero las veo así, por Internet... porque me encantan (Agustina, 17 años, Quilmes Centro).

\footnotetext{
${ }^{9}$ Series como Ones Upon a Time o The Walking Dead son las preferidas por una generación de 14 a 22 años de edad y de diferentes géneros, clases comunicacionales y sociales. Las jóvenes mencionan Ones Upon a Time, una historia que mezcla los cuentos de hadas de antaño con la ciencia ficción televisiva. Por su parte The Walking Dead revive las historias de muertos vivos a lo George Romero de los ochenta, con una impronta de acción y en episodios semanales que crean adicción.
} 
Yo tengo una página que se llama Series Yonkis o en Cuevana y eso no porque andan re lentos. No, Cuevana no. Y hay otra que se llama MonsterDivx, pero más que nada para descargar películas, no las miro desde ahí (Agustina, 17 años, Quilmes Centro).

Sí, ahora tengo películas, y Sherlock. Sherlock sí la tengo, las bajé de MonsterDivx. Porque tiene la opción, me las bajé con los dos subtítulos, en español y en inglés. Me encanta, estoy esperando la tercera temporada y no sale más (Agustina, 17 años, Quilmes Centro).

Por ejemplo, me encanta Friends, pero bueno, terminó en el $2004 \ldots$ así que ya no la puedo seguir. Pero la que sí seguía era Two and a Half Men, pero cuando se fue Charlie Sheen la serie como que se murió y no la vi nunca más, pero nunca más, eh (Facundo, 20 años, Quilmes Centro).

Veo Aliados y después, otra serie, por ejemplo, la novela de la noche, Los vecinos en guerra. Por ejemplo, Cumbia Ninja. Es como muy fantasioso, pero está bueno (Talía, 14 años, San Francisco Solano).

En el caso de las comedias, proponen un tipo de humor que se presenta como una impronta interesante de señalar. Cada sociedad y cada cultura -apelando a una acepción de cultura/s geográficas- tienen una relación particular con su humor. Las series estadounidenses, en abundantes casos, explotan su humor en situaciones y gags consecutivos que generan proximidad con los televidentes de gran parte del mundo. Esta también es una negociación de sentido. Los jóvenes que prefieren Friends o Los Simpson se ríen de un humor que llegó a ser global, pero a la vez no borra las bases de su localidad. Se produce una apropiación-siguiendo a Silverstone-, concepto que no trata solamente de hacer propias mercancías físicas sino también mensajes. En estos casos de apropiación se pasa a una incorporación, entendida como esa invisibilización de la génesis de las prácticas tornándolas naturalizadas, cuando ya forman parte de la vida cotidiana, de los usos -podría decirse de la identidad- del sujeto de la acción.

La configuración identitaria con series extranjeras tiene fuerte arraigo en las tecnologías de la comunicación. Estas permiten una progresión de usos creativos por parte de los jóvenes.

En YouTube existen los llamados fanvids, los cuales son videos realizados por jóvenes internautas fanáticos de una serie quienes mediante un programa de edición de video recortan partes de la serie y crean una nueva narración en la cual suceden cosas que en la serie original no sucedieron, satisfaciendo sus ansias de creación. Una característica del "nativo digital" también llamado en esta faceta "prosumidor"- es también formar parte de la narración que ve, proponiendo o discutiendo en foros con los realizadores o con pares, creando nuevas narraciones con el sólo fin estético de compartir. Asimismo, hubo series como Lost en la cual los productores David Lindeloff y Carlton Cruse mantenían contacto en video mediante preguntas y respuestas sobre la serie con sus fans.

Las nuevas tecnologías de la comunicación se van capitalizando por parte de los jóvenes televidentes y también de los realizadores, quienes entienden que el público va cambiando y lejos de aquel receptor pasivo que enunciaba la Mass Comunication Research, o incluso 
avanzando también en la idea de decodificador que proponía Stuart Hall (1979) en Encoding/Decoding para pensar la relación con los medios audiovisuales. Dado que el decodificador, empleando su capacidad racional ante el mensaje codificado, podía proponer decodificaciones dominantes, negociadas o de oposición en sus círculos de influencia y así tomar decisiones cotidianas ante las noticias que le llegan; mientras que en los casos planteados se avanza un paso más, ya que ante los medios digitales el decodificador puede hacer escuchar o ver ante los codificadores estas posiciones mediante foros, correos electrónicos o comentarios en redes sociales virtuales.

Asimismo, no solamente la televisión se desplaza a nuevas pantallas, sino también el cine. Páginas al estilo Cuevana proveen la posibilidad de ver películas nuevas, inclusive en cartel.

El cine más que una industria cultural y un arte es en términos comunicacionales una experiencia. Compartir un espacio en la oscuridad con desconocidos y con amigos donde comentar la película luego, comer pochoclos y quedarse quieto y atento durante dos horas se torna una experiencia que se desplaza mediando una pérdida a las más diversas maneras de ver una pantalla de computadora o tablet. En el hogar, en la calle, acostado o sentado, pausando para ir a hacer cosas y retomando la historia en otro momento, el fundamento del cine en nuevas pantallas es otro. El cine es un consumo asiduo por parte de nuestros jóvenes informantes.

Veía Once upon a time, que la empecé pero después no la seguí más. Lo que veo casi todos los días o día por medio son películas en Cuevana (Joaquín, 15 años, Quilmes Centro).

Antes veía Cuevana, algunas comedias bastante tontas para despejarme, algunas tipo Transformers e incluso me ponía al día con clásicos como Scarface y esas cosas, igual no vi tantas, tantas películas. Habré visto unas 10 o algunas más, pero con el quilombo se complicó (Fernando, 24 años, Quilmes Centro).

Antes era como que se descargaban más películas, ahora es más de mirarlas online. En Cuevana. Pero antes sí se bajaban más películas. Pero eran películas que por ahí las veías y decías: "uy, mirá, está película va a estar buena", porque es de acción o alguna comedia (Facundo, 20 años, Quilmes Centro).

¿Películas? Si veo, de vez en cuando. No las bajo porque todavía, traté de hacerlo pero no me salió todavía (Aldana, 16 años, San Francisco Solano).

Pero vos buscas el nombre de la película que queres ver y te parece para descargar o verla así, las veo ahí (Micaela, 14 años, San Francisco Solano).

Las películas, algunas las guardo, si están buenas las guardo si no las miro online. Tengo la de Buscando a Nemo, tengo la de Rápido y Furioso 5 y la 6 y tengo algunos capítulos de The Walking Dead, porque me gusta, si están buenos me gusta verlos otra vez (Nicolás, 16 años, Bernal Oeste).

A su vez, cuando la solución es comprarlos se populariza entre los jóvenes otro tipo de transacción, adquirir las películas, series, CDs de música y videojuegos en el mercado paralelo de los manteros y locales de copias truchas. En palabras de una entrevistada: "Por Internet no 
miro películas generalmente, voy y compro. Piratas, obvio. En el Outlet (risas). O en la calle, digo" (Marina, 20 años, Don Bosco).

Copias truchas de los originales, las cuales dada la tecnología digital tienen las mismas prestaciones -lo que torna confuso el estatuto de un original en la cultura digital-, se ofrecen a muy bajo costo en las calles de cualquier centro comercial de Quilmes. La peatonal Rivadavia de Quilmes Centro, el Outlet de la calle Yrigoyen, la calle 844 de San Francisco Solano, el cruce a San Francisco Solano de Villa La Florida y la puerta del Quilmes Factory Shopping, en la avenida Calchaquí de Quilmes Oeste, son solamente algunos lugares donde se ubican los manteros.

Las resistencias parecen transitar diferentes terrenos. No obstante el mercado ilegal maneja importantes sumas de dinero, y adquirir los productos de los manteros se torna una manera resistente ante los argumentos de la propiedad privada del derecho de autor. En ese intercambio comercial de los dispositivos de almacenamiento, los jóvenes no se ven a sí mismos como piratas ni al mantero como a un delincuente. La práctica de consumo en los márgenes -si bien se trata de una compra en la que media el dinero- en el imaginario puede asemejarse a "colgarse del cable" o "robar" wifi de un vecino, otros modos "piratas" de acceder a la industria cultural posmoderna. La compra de truchos se expresa en los discursos como una opción más de acceso, en el mismo rango que la televisión tradicional y a la descarga y visualización en internet.

Series ahora estoy mirando una nueva que salió que es Cumbia Ninja. Estoy esperando que empiece The Walking Dead. Después C.S.I. Si algún capítulo me lo pierdo, lo veo por la computadora. La primera temporada y la segunda las vi por DVD, los compré en una disquería grabados (Nicolás, 16 años, Bernal Oeste).

Toda industria de la cultura plantea dinámicas de producción, circulación y consumo. En el caso de las editoriales, los libreros de oficio fueron un eslabón necesario en el circuito de consumo no solamente por ser los minoristas que acercan las obras a los públicos sino también por contar con un conocimiento específico de estas obras. Las grandes cadenas de librerías, con empleados no especializados en libros, ayudan a un borramiento de esta especificidad. Lo cierto es que en librerías tradicionales el librero ocupa un rol cultural de primer orden ya que no solamente vende libros sino que los conoce, en muchos casos los leyó y de allí que los recomienda. Este rol social en medio de la digitalización se transmuta muchas veces a los foros y redes sociales virtuales de recomendación de lecturas, booktubers, como a comunidades de sentido específicas alrededor de determinados consumos culturales. Desde allí, nos interesan los roles de estos mediadores culturales que en la contemporaneidad se encuentran reunidos bajo lógicas basadas en participar y compartir.

En el caso de las películas y series de televisión, en la actualidad su principal vía de circulación y consumo son las plataformas gratuitas de Internet en las que se distribuyen completas, muchas veces en buena calidad, con subtítulos en diferentes idiomas, con la 
posibilidad de realizar comentarios y puntuarlas, aunque por fuera de un espacio controlado por el mercado y de los controles del derecho de autor. Por su parte, existen otros espacios de circulación como compartir archivos descargados de Internet o copiados de originales mediante dispositivos extraíbles de almacenamiento o enlaces en la nube. Estos últimos, un tanto más interpersonales que comunitarios no distan mucho a la práctica del préstamo de un libro, un CD o un DVD. En última instancia nos interesa ahondar en una práctica no gratuita, aunque con menores costos que los originales, y que se encuentra en los márgenes del mercado. La práctica de compra y venta de copias de CDs y DVDs en el mercado informal se sintetizan en el mantero como nueva figura en este circuito de circulación industrial.

El nombre mantero proviene de su impronta identitaria, formal y estética, a la hora de presentarse en la escena comercial: se trata genéricamente de sujetos que despliegan una manta -una tela, o papeles- en el suelo de una vereda, una feria, una plaza y ubican sobre esta base sus mercancías. Al tratarse de copias ilegales de discos de música, películas y series televisivas, no lo hacen en locales a la calle ni en galerías, aunque existen prácticas de locales que venden otros productos autorizados y ofrecen, además, estas copias. El mantero, en su práctica cotidiana, oficia como el librero porque en su venta no solamente envuelve los discos y los cobra sino que tiene algo para decir de las series y películas que vende, las divide por género, por novedad y las recomienda según el gusto del cliente. En el devenir de las observaciones y charlas informales se reafirma esta perspectiva, son mayoría los clientes que se acercan sin buscar un título predeterminado sino que consultan por lo nuevo en terror o en comedia, por la serie de moda o por la película que se le pueda recomendar.

Finalmente, YouTube se erige como un espacio cotidiano donde buscar los más diversos videos y no solamente series televisivas. Otra vez una empresa multinacional como Google aparece en el discurso juvenil.

En el paradigma de las nuevas pantallas en YouTube tiene preponderancia la visualización de series y películas -es decir viejas pantallas-, pero en usos específicos de estas. En diversos casos cuentan que miran partes de series y de películas. Esto es una apropiación específica de este medio. Nadie podría buscar en televisión o ir al cine a ver una parte de la historia, ni siquiera sería práctico alquilar una película para ver una escena. La demanda a la carta de partes de narraciones audiovisuales conocidas es un uso habitual propio de YouTube.

YouTube se transforma, entonces, en una biblioteca de Alejandría posmoderna (De Cicco, 2008), deviniendo en un reservorio de formatos ya conocidos que pueden ser buscados específicamente.

En YouTube miro videos graciosos o de música o capítulos de Alf, algunas partes de Los Simpson o El Chavo (Lucas, 14 años, Villa La Florida).

En YouTube a veces veo cuando no me sale, o cuando quiero tocar una canción en la guitarra, por ahí veo tutoriales que te enseñan o videos así específicos de Los Simpson. 
Por ahí, me acuerdo de un capítulo, o de una parte, y vi eso (Nair, 18 años, Quilmes Centro).

A veces cuando estamos en la casa de mi amiga vemos ahí, buscamos algunas cosas de terror para ver, cuando estamos aburridas. La última vez que vimos era la historia de Hello Kitty. Era que contaba la historia de Hello Kitty, cómo se hizo en la vida real, que todo empezó por un laberinto, todo eso y nosotras decíamos no hay nada de Hello Kitty acá (Talía, 14 años, San Francisco Solano).

En este sentido la memoria audiovisual tiene un lugar colaborativo y universal -porque en YouTube son los usuarios quienes postean los videos. En este marco, el uso habitual tiene como protagonistas a dos relatos: el videoclip y el tráiler, uno televisivo y otro cinematográfico. Perfectos formatos para nuevas pantallas, dadas sus características de discursos autónomos y breves.

La música es un tema recurrente a la hora de tematizar YouTube ya que es una vía rápida para acceder a las canciones.

En YouTube veo videos de música, de todo, no sé. No te va a gustar, La Vela (Marianela, 19 años, Quilmes Centro).

Miro muchos videos de Callejeros y las letras que te aparecen, después los incidentes que pasan también en los recitales, en los recitales en vivo, también veo el de Los Redondos, el Indio Solari (Aldana, 16 años, San Francisco Solano).

YouTube lo uso para escuchar música, para ver los videos de música (Nicolás, 16 años, Bernal Oeste).

Hay veces, ponele, no sé, algún chico que sale en un videoclip de alguna cosa graciosa, ponele. Si no para escuchar música. Busco la canción, la que me gusta a mí, y la veo (Lautaro, 17 años, Quilmes Centro).

En otras publicaciones se trabajó el concepto de "nuevas pantallas" y allí la preocupación fue construir nociones sobre los formatos que nacieron para internet y telefonía móvil. Se investigó sobre las lógicas de producción, de circulación y de consumo. Se conocieron así casos exitosos en el mundo como la serie Malviviendo que contó con tres temporadas y una gran cantidad de seguidores a nivel mundial. En trabajos como "Nuevas pantallas frente al concepto de televisión" (Murolo, 2009) o "Nuevas pantallas: un desarrollo conceptual" (Murolo, 2012) se puso de relieve el cambio de época en las narraciones audiovisuales.

Sin la apropiación social, las tecnologías están condenadas al desuso y la obsolescencia, como sucedió con tantas apuestas en relación a tecnologías de la comunicación. Siguiendo a Raymond Williams (2011) no nos posicionamos ante una mirada determinista. Tanto en su versión de "determinismo tecnológico", o al entenderla como una "tecnología sintomática" y por lo tanto "síntoma" de una sociedad que la determina. De ello que el juego entre sujetos y tecnologías se da, fundamentalmente, en los usos y apropiaciones, en el lugar simbólico que ocupan las tecnologías en la cotidianeidad generando prácticas comunicacionales de incorporación y conversión en sociedad. 


\section{Los piratas de la pantalla pirata}

Los jóvenes no asumen ser piratas, se trata de una identidad atribuida por el mercado y no asumida por los usuarios. Descargar películas y series, música, videojuegos y libros es una práctica usual. Los teléfonos móviles y las computadoras personales de la mayoría de nuestros entrevistados alojan material descargado de internet.

Existen diversos usos en la descarga y visualización de material con derechos de autor. La mayoría de los jóvenes coincide en los sitios de descarga de material y esto hace que haya una conciencia de época generalizada que señale estos portales de internet como parte de la socialización habitual entre los jóvenes. Por lo tanto, existe entonces una hegemonía de estas empresas. En estos portales como Cuevana y Taringa (nacionales) o SeriesYonkis (español) se puede descargar el material sin ser un usuario logueado (registrado) o registrarse y tener acceso a poder postear comentarios, puntuar y llevar un registro de las actividades. Algunos jóvenes acceden a este uso más activo de la conformación como "piratas".

El acceso a material de la industria cultural digital sin derechos parece no estar mediado por una crítica por parte de los jóvenes, aún pidiéndoles una reflexión al respecto hay quienes evaden la "acusación" del sistema. En menor medida, unos pocos asumen alguna "culpa" y hay quienes argumentan la práctica.

Puede ser delito desde la perspectiva legal actual, pero ya es obsoleta. La ley muta, pero va más lenta que la evolución de las ideas o las necesidades sociales. Es un delito, tal vez sí en términos de las normativas vigentes. ¿Debería serlo? No. Porque hay gente que puede decir "ok, yo hice este libro, lo registré y no veo un mango" y por el otro lado hay millones de personas que se benefician con eso. O sea, no es una relación win-win evidentemente, y como casi todo en la vida. Ahora bien, podés buscar alternativas, como si queres bajar este libro, comete el anuncio de Gucci y Coca-Cola y parte de la guita del anuncio va al escritor, cosas así, innovar, no hacer mierda todo (Fernando, 24 años, Quilmes Centro).

Este tema se dio hace poco con la ley SOPA y yo creo que la piratería es la principal fuente para que se interesen en el contenido que vos descargás porque si eso verdaderamente te gusta o te interesa, vos vas y lo comprás, pero no vas a ir a comprar algo que vos no sabés qué es. Los juegos es la principal demostración de eso, porque vos los juegos los podés descargar de cualquier lado, los podés conseguir de cualquier lado, no originales por supuesto. Pero si vos querés ese juego, si te gusta realmente, vos vas a ir y te lo comprás (Joaquín, 15 años, Quilmes Centro).

Tendría que estar aceptado y buscar alguna manera que la gente con los derechos de autor tenga alguna retribución por eso, pero no sé, no se va a dejar de hacer (Marianela, 19 años, Quilmes Centro).

En parte sí tienen razón porque las personas, los que hacen música piensan en hacer un álbum y si vos compras, supuestamente, la plata, parte de la disquera, supuestamente, una parte va para ellos, supuestamente es lo que dicen y es como que vos no pagas porque es verdad, es una rata y yo ya dije prefiero bajarme tres temas que me gustan a 
comprarme un cd que tengan como diez que no me gustan y tres que sí (Aldana, 16 años, San Francisco Solano).

Usamos el derecho del autor y por su lado tienen razón porque se están haciendo esas cosas para obtener una ganancia, nosotros como que se la estamos quitando (Nicolás, 16 años, Bernal Oeste).

En los discursos aparecen ideas que proponen solucionar el conflicto. El modelo de negocios asentado en la publicidad o la creencia que acceder al material sin comprarlo, a modo de prueba, es un trampolín hacia su compra, son respuestas a la pregunta sobre qué hacer con la piratería. Por otra parte son varias las voces que señalan el precio excesivo de la industria cultural y por ello es una opción -o una escapatoria- la descarga y visualización digital.

Pienso que si bajaran los precios la gente tendría más acceso fácilmente a esos productos, no tan caros. Por ejemplo, los libros, que son fuente de conocimiento y un montón de cosas, están re caros y la gente que se quiere culturizar no puede porque a veces tienen que elegir entre eso o comida u otra cosa que necesiten. $Y$ eso me parece mal porque los libros los necesita, todo el mundo necesita un libro por lo menos. Me parece cualquier cosa, un desastre. Tienen que bajar más los precios de todo. Es una sociedad consumista. Yo soy consumista. Amo comprar (Agustina, 17 años, Quilmes Centro).

El crecimiento de la piratería va de la mano con aumento de los precios. Porque antes un $C D$ te salía $\$ 10, \$ 5$. Ahora te comprás un $C D$, te sale $\$ 70$. ¿Quién va a comprar un $C D$ a $\$ 70$ ? O sea, está bien, $\$ 70$ hoy en día no es nada, no es nada, no hacés nada (Facundo, 20 años, Quilmes Centro).

A veces no tenes la plata para comprarte cosas y preferís descargarlo. Y mucha gente lo hace y a veces te dicen eso, él también lo está haciendo pero prefiere decírtelo a vos, pero a veces la gente no tiene la plata necesaria o no consigue los discos que quiere tener y los tiene que descargar. Es como otra opción, en vez de comprarlo, lo podes descargar (Micaela, 14 años, San Francisco Solano).

En sí no está bien, ponele, el hecho de descargar las películas o los videos, y todo eso, pero por ahí la realidad es que ir a comprar un DVD original es muy elevado el costo por ahí a veces para comprar un CD y que lo uso dos veces, me cansé y no lo escucho más. Entonces, por ahí es como una alternativa que sí, que no la veo mal porque no voy a gastar tanta plata porque yo no trabajo y la plata que me dan mis viejos no la uso para ir a comprar un CD porque no quiero ser un pirata. No, para mí no está tan mal o de última que te lo vendan algo más accesible, o que te lo vendan online. No, no lo veo mal a eso. (...) porque no entiendo nada de todo lo que hacen (Lautaro, 17 años, Quilmes Centro).

El objeto CD o DVD "original" -producido en serie por las discográficas y cinematográficas-, ante la reproductibilidad técnica y la baja de la demanda, pasa a ser un bien escaso, muchas veces de colección o de fetiche. La caja, el librito con las descripciones del contenido, las fotos de los artistas y los extras que trae la versión original son el plus que un fanático o un sibarita de la industria cultural está dispuesto a conseguir mediante un pago extra al de la versión trucha. Obviamente que en la era digital esos textos, fotografías y extras no son inconseguibles. Sin embargo, se trata de un índice del cambio en el estatuto de aura que advertía Walter Benjamin como metáfora y metonimia de la obra de arte, ya que alrededor de la industria cultural, aún 
serializada, mercantil y objetual se despliegan atisbos de deseo a la cosa como única -con su propio aquí y ahora-, por lo tanto, con poderes entre sublimes y conformistas.

Los objetos en general también cuentan historias y los objetos culturales en particular traen consigo una carga de sentido que relaciona, por ejemplo, una canción o una escena con un momento o una persona. Se trata de ese valor simbólico que excede a los de uso y de cambio. De allí la mismidad atribuida a una porción de plástico o de papel, tan igual y a la vez tan distinta a otra similar en apariencia.

\section{A modo de cierre: cuestiones de capital cultural}

Nuevos modos de acercarse a los productos culturales, de consumirlos, apropiárselos, objetizarlos, incorporarlos y convertirlos (Silverstone y otros, 1997) también predisponen -en términos bourdieanos- nuevas configuraciones de capital cultural. Comprar objetos de la industria cultural es una forma de acercarse a discos, películas, libros, videojuegos tal como la conocimos durante el siglo XX. A finales de este siglo y comienzos del XXI el enriquecimiento del capital cultural sigue estando ligado por la cantidad y calidad de libros que leímos, de películas que vimos, de música que escuchamos, de videojuegos que jugamos. Porque la industria cultural posee esos valores simbólicos que contienen elementos necesarios para la configuración de nuestras identidades: otras identidades, ideología, representaciones e imaginarios del mundo.

Cuando se trata este tema en trabajos académicos generalmente se reduce el problema a una disputa de intereses entre las discográficas y cinematográficas que protegen sus ganancias y los internautas que quieren acceder a los materiales sin restricciones. La reducción estriba en que se busca una solución al tema desde la mirada del mercado que es quien pierde dividendos, al tiempo que se deja de lado un universo simbólico de problemáticas comunicacionales ligado a las prácticas sociales generadas alrededor de los productos culturales. Estos usos que generan nuevos estatutos del capital cultural son a nuestro entender el punto a focalizar.

La diferencia contemporánea se ubica en que los jóvenes en su mayoría no compran masivamente industria cultural -ni sus padres la compran para ellos- sino que se la procuran de manera colaborativa. Es importante subrayar que no se trata solamente de una preferencia: la mayoría de los jóvenes nos dice que de no haber accedido al material de esta manera no lo hubiera podido comprar. Sostienen que los discos son muy costosos, que las entradas al cine escapan de su poder adquisitivo y hasta hay casos como el de Agustina, que puntualiza preferir utilizar ese dinero para salir a comer hamburguesas con sus amigos. En este sentido argumenta: "Al Cine no voy tanto, fui la última vez el año pasado a ver mi película favorita, Titanic en 3D. Sí, 
fue lo mejor. Y... después nunca más... está re caro también el cine. Prefiero gastar esa plata en otra cosa, en McDonald's" (Agustina, 17 años, Quilmes Centro).

Este dato es esencial porque pone de relieve el doble valor que le otorgan a estos objetos culturales: todos hacen "uso" de ellos y forman parte importante de su identidad como jóvenes, pero a la vez no le otorgan un valor monetario que deba ser pagado a como dé lugar. En otras palabras, en la subjetividad juvenil contemporánea parece subyacer la idea de que los productos culturales no deberían ser comprados, los cuales se procuran de modo colaborativo en primera instancia y en contados casos pagar por ellos.

Facundo sentencia: "Pero claro, ¿para qué lo vas a comprar si lo tenés gratis?" (Facundo, 20 años, Quilmes Centro). Como característica propia de época, se marginan los objetos culturales de otras mercancías como pueden ser los alimentos o la ropa. La industria cultural posee un valor simbólico que supera al valor de cambio y este parece ser el punto que se connota en los discursos de los jóvenes.

Agustina dice: "Tengo CDs. De los que me gustan y quiero tener, los tengo. Tengo varios, me gusta tener los CDs y truchos no me gusta tenerlos, me gusta tener el original. $Y$ si de alguna banda o artista que me gusta, sale nuevo, me lo voy a comprar" (Agustina, 17 años, Quilmes Centro).

Asimismo, no se deja de subrayar que en todo momento el tema debe ser pensado desde la dimensión de la clase social. Agustina cuenta con el dinero para comprar el CD, -los que quiere tener los tiene- o elige administrarlo de otra manera, por ejemplo en un gusto como locales de comidas rápidas. Sin embargo, otros jóvenes que no pueden comprarlos y cuentan con el dinero que le dan sus padres para necesidades básicas acceden al material, principal y muchas veces únicamente, descargándolo o al ser compartido por amigos. El tema, desde una mirada macro del mercado o desde la visión micro de la más llana interacción social, se trata en primera instancia de flujos de capital económico. Sin embargo, nos interesa advertir la dimensión simbólica que trae consigo el intercambio y la acumulación de capital cultural. Entonces es cuando la hegemonía es desafiada por apropiaciones sociales devenidas en incorporaciones, hábitos y prácticas. Desde este terreno firme de lo "naturalizado", las resistencias tienen argumento histórico y devienen -mediando una lucha cultural- indefectiblemente en derechos. A la hegemonía, siempre atenta y dinámica por definición, sólo le queda contrarrestar y ceder en igual medida procurando incorporar la posición demandante y aquietando cualquier posibilidad de cimentación contrahegemónica.

Como sea, tanto quienes pueden adquirir el original como quienes no, incorporan la práctica de la descarga y visualización en internet. Salvo en casos como el fanatismo hacia algún artista que merezca comprar su CD para tener el librito de canciones y apasionarse viendo sus fotos, parece no haber excusas para la compra del original. En efecto, se dice: "Algunos los he comprado porque obviamente el CD trae cosas que uno grabado no lo trae. Hay un bonus track o ya el hecho de tenerlo material y decir: "tengo el CD...", qué se yo, estoy armando de a 
poco la colección de los CDs de Nirvana, de Los Redondos, de Ska-P que es mi banda favorita" (Facundo, 20 años, Quilmes Centro).

Quienes saben dicen que suena mejor el disco original pero eso poco importa cuando en frente se encuentra la gratuidad. Además, los usos que se les daría al objeto determinan de algún modo la compra o no del CD musical. Los jóvenes escuchan su música en su teléfono móvil o en la computadora, por lo cual convierten las canciones de los CDs al formato mp3 que pesa poco y puede trasladarse en dispositivos móviles, lo que hace que de todos modos baje la calidad del sonido. En ese caso, el CD original queda obsoleto. La música parece ser uno de los materiales más descargado y compartido por los jóvenes. Sus teléfonos contienen canciones y las escuchan en momentos de ocio, tareas escolares y no lugares. Al tiempo que no es un uso masivo en la computadora, donde ocupan un lugar importante los formatos audiovisuales, libros y videojuegos.

La descarga de material de internet se experimenta como una condición de época. Es una práctica social y como tal no se reflexiona sobre sus orígenes y no se la cuestiona. El problema es de quien se ve afectado. Así se manifiesta: "Pero la mayoría, casi todos estaban en contra de eso, pero si vamos al caso, todo el mundo lo hace, no me pueden decir a mí que yo no haga ese tipo de cosas cuando esa persona también lo hace. Eso es lo que opino. No está ni bien ni mal, es algo normal, que últimamente paso" (Aldana, 16 años, San Francisco Solano).

La lucha por la hegemonía de los sentidos es evidente, los usos y apropiaciones están proponiendo nuevos modos de consumo que no necesitan el objeto CD en el caso de la música, inclusive del objeto DVD en el caso de las temporadas de series o de películas, las cuales podrían estar guardadas en formatos como avi o $\mathrm{mpg}$ en pendrives y discos rígidos de netbooks o tablets para ser vistas en estas nuevas pantallas.

Existe en la contemporaneidad una conciencia en relación a compartir materiales culturales que lo elevan a la categoría de derecho. Como ciudadanos del universo digital los jóvenes tienen la potestad de darle a conocer a sus amigos -y en otros casos a la comunidad toda- los productos culturales a los que acceden y con los cuales incrementan sus capitales culturales. La colaboración es entonces el germen del modelo social que impera y que se contrapone a la economicista idea clásica de propiedad privada.

Las comunidades digitales -mayormente juveniles- parecen erigir sus propios regímenes de sociabilidad en los cuales compartir y colaborar se postulan como la apoteosis modélica del vivir juntos. Es cierto que estas comunidades virtuales no se encuentran por fuera ni por encima de la sociedad "presencial" y que deben ceñirse a sus reglas y leyes -más allá de los parches, obsolescencias y vacíos legales que todavía hay en materia digital. Sin embargo, lo virtual forma parte sustantiva de la sociedad, ya que allí generamos cada vez más prácticas de sentido y nos relacionamos. Por lo cual debe atenderse a los modelos que la virtualidad propone y más aún si tienen como base la solidaridad y el intento por una libertad de acceso a las más diversas 
producciones de información, comunicación, entretenimiento y conocimiento. De alguna manera, a una concreción de determinados derechos humanos.

\section{Referencias bibliográficas}

Adorno, T. y Horkheimer, M. (1970). Dialéctica del lluminismo. Buenos Aires: Sur.

Bauman, Z. (2009) (2000). Modernidad líquida. Buenos Aires: Fondo de Cultura Económica.

Bourdieu, P. (2006) (1980). La distinción. Criterio y bases sociales del gusto. España: Taurus.

Bourdieu, P. (2007). El sentido práctico. Buenos Aires: Siglo XXI Editores.

Bugvila, A. V. (2012). El mapa no es el territorio (Ponencia). En VII Jornadas de Sociología de la Universidad Nacional de La Plata "Argentina en el escenario latinoamericano actual: debates desde las ciencias sociales". La Plata, Argentina. 5 al 7 de diciembre de 2012.

De Certeau, M. (1996). Capítulo III. Valerse de: usos y prácticas. En La Invención de lo cotidiano. 1. Artes de hacer. México D.F.: UIA.

De Cicco, J. (2008). YouTube: el archivo audiovisual de la memoria colectiva. Buenos Aires: Universidad de Palermo.

Doueihi, M. (2010). La gran conversión digital. Buenos Aires: Fondo de Cultura Económica.

Hall, S. (1979). Encoding/Decoding. En Culture, Media, Languaje. Working Papers in Cultural Studies, $1972-79$ (pp. 128-138). Londres: Hutchinson.

Jenkins, H. (2010). Piratas de textos. Fans, cultura participativa y televisión. España: Paidós Comunicación.

Jenkins, H. (2006). Convergence culture. La cultura de la convergencia de los medios de comunicación. España: Paidós Comunicación.

Moreno Muñoz, M. (2012). El cierre de Megaupload y los cowboys de la S.O.P.A.: Conflicto de valores en la era de Internet. En Ciclo: Para comprender nuestro tiempo. España.

Moreno Muñoz, M. (2012). Propiedad intelectual, seguridad y control de las comunicaciones en Internet. Impacto sociocultural del fenómeno Megaupload. En Gazeta de Antropología, 28 (2).

Murolo, N. L. (2014). Hegemonía de los sentidos y usos de las tecnologías de la comunicación por parte de jóvenes. Estudio realizado en Quilmes 2011-2014. (Tesis doctoral). Facultad de Periodismo y Comunicación Social, Universidad Nacional de La Plata. Disponible en: http://sedici.unlp.edu.ar/handle/10915/43080

Murolo, N. L. (2009). Nuevas pantallas frente al concepto de televisión. Un recorrido por usos y formatos. En Razón y Palabra, Primera Revista Latinoamericana Especializada en Comunicación, México, 69. Disponible en http://www.razonypalabra.org.mx 
Murolo, N. L. (2010). Post-zapping: transmite tú mismo. YouTube como la televisión posmoderna. En Razón y Palabra, Primera Revista Latinoamericana Especializada en Comunicación, 71. Disponible en http://www.razonypalabra.org.mx

Murolo, N. L. (2012). Nuevas Pantallas: Un Desarrollo Conceptual. En Razón y Palabra. Primera Revista Digital en Iberoamérica Especializada en Comunicología, 80. Disponible en http://www.razonypalabra.org.mx

Silverstone, R.; Hirsch, E. y Morley, D. (1996). Tecnologías de la información y de la comunicación y la economía moral de la familia. En Silverstone, R. y Hirsch, E. (Eds.) Los efectos de la nueva comunicación. El consumo de la moderna tecnología en el hogar y en la familia (p. 45). Barcelona: Bosch

Williams, R. (2011). Televisión. Tecnología y forma cultural. Buenos Aires: Paidós. 